\title{
Effectiveness of Herbal and Non-Herbal Toothpastes in Reducing Dental Plaque Accumulation
}

\author{
Citra L. Yuwono', Benny M. Soegiharto², Fadli Jazaldi² \\ ${ }^{1}$ Undergraduate Program, Faculty of Dentistry, Universitas Indonesia, Jakarta 10430, Indonesia \\ ${ }^{2}$ Department of ortohodontics, Faculty of Dentistry, Universitas Indonesia, Jakarta 10430, Indonesia \\ Correspondence e-mail to: sc_you_meiji@yahoo.com
}

\begin{abstract}
Maintaining good oral hygiene in orthodontic patients is important and as the community interest in herbal ingredients increases, herbal toothpaste was developed. Its effectiveness against dental plaque accumulation is still under debate. Herbal toothpaste has not been tested in fixed orthodontic patients. Objective: To study the effectivenes differences between herbal toothpaste and non-herbal toothpaste. Methods: This randomized, double blind clinical trial was participated by 16 subjects aged range 15-35 years who were planned for fixed orthodontic. The subjects were divided into two groups based on the type of toothpaste used. Plaque accumulations were measured according to Löe and Sillness plaque index on Ramfjord teeth before and two weeks after bonding. Results: Wilcoxon test result showed there was no significant reduction of plaque index on herbal toothpaste usage nor significant increase on non-herbal toothpaste usage. Mann-Whitney test showed no significant differences between herbal and non-herbal toothpaste. Conclusion: There was no significant differences in plaque acummulation between usage of herbal toothpaste nor usage of non-herbal toothpaste. There was no significant effectiveness differences between those toothpastes in fixed orthodontic patients, although herbal toothpaste usage showed a reduction of plaque index, whereas non-herbal toothpaste usage showed an increase of plaque index.
\end{abstract}

\begin{abstract}
ABSTRAK
Efektivitas pasta gigi herbal dan non-herbal dalam mengurangi akumulasi plak. Mengingat pentingnya menjaga kebersihan mulut pada pasien ortodonti dengan alat cekat dan seiring dengan meningkatnya minat masyarakat akan bahan herbal, pasta gigi herbal pun dikembangkan. Namun, efektivitas pasta gigi tersebut terhadap akumulasi plak masih diperdebatkan. Tujuan: Mengetahui perbedaan efektivitas pasta gigi herbal dengan pasta gigi non-herbal. Metode: Penelitian uji klinis randomisasi, buta ganda ini diikuti oleh 16 subyek penelitian berusia 15-35 tahun yang akan menggunakan alat ortodonti cekat. Enam belas subyek tersebut dibagi menjadi dua kelompok sesuai dengan pasta gigi yang akan mereka gunakan dan diukur akumulasi plaknya dengan indeks plak Löe dan Sillness pada gigi Ramfjord sebelum dilakukan bonding braket dan dua minggu setelah bonding braket. Hasil: Uji kemaknaan Wilcoxon menunjukkan tidak terdapatnya penurunan indeks plak yang bermakna baik yang terjadi pada penggunaan pasta gigi herbal, maupun peningkatan indeks plak yang bermakna yang terjadi pada penggunaan pasta gigi non-herbal. Hasil uji Mann-Whitney pun menunjukkan tidak terdapatnya perbedaan yang bermakna antara efektivitas pasta gigi herbal dan pasta gigi non-herbal. Simpulan: Tidak terdapat perbedaan akumulasi plak yang bermakna antara sebelum dan setelah pemakaian pasta gigi herbal ataupun pasta gigi nonherbal. Serta tidak terdapat perbedaan efektivitas yang bermakna secara statistik antara kedua pasta gigi tersebut pada pasien ortodonti dengan alat cekat.
\end{abstract}

Key words: dental plaque, fixed orthodontic, herbal toothpaste, non-herbal toothpaste

\section{PENDAHULUAN}

Seperti perawatan lain pada umumnya, perawatan ortodonti juga memiliki resiko dan komplikasi tersendiri. Salah satunya adalah terjadinya peningkatan akumulasi plak yang disebabkan oleh adanya kesulitan dalam membersihkan gigi, terutama pada daerah servikal permukaan gigi dari braket atau di bawah kawat gigi. Hal ini dapat meningkatkan resiko terjadinya demineralisasi gigi dan kelainan jaringan 
periodontal. $^{1-5}$ Pencegahan terjadinya hal tersebut dapat dilakukan dengan menjaga kebersihan mulut pemakai alat ortodonti cekat. Menjaga kebersihan mulut secara sederhana dan efektif dapat dilakukan dengan cara menggosok gigi. Jenis pasta gigi yang digunakan merupakan salah satu faktor yang berperan di dalamnya. ${ }^{6-9}$

Saat ini, telah dikembangkan pasta gigi herbal sesuai dengan meningkatnya minat masyarakat terhadap penggunaan bahan alami. ${ }^{10-12}$ Salah satu jenis pasta gigi herbal yang akan digunakan dalam penelitian ini adalah pasta gigi yang mengandung sodium bikarbonat, fluoride, dan berbagai ekstrak herbal seperti ekstrak rhatania (Krameria triandra), sage (Salvia officinalis), dan chamomile (Matricaria recutita). Ketiga ekstrak herbal yang terkandung dalam pasta gigi herbal tersebut diketahui berfungsi sebagai agen antiinflamasi, antipendarahan, dan dapat memperkuat gusi dan jaringan. Echinacea diketahui sebagai antiinflamasi dan antipendarahan, dan berpotensi memperkuat sistem imun. Myrrh (Commiphora molmol) dapat berfungsi sebagai antiinflamasi, antipendarahan, dan antiseptik, serta dapat memperkuat gusi dan jaringan. Yang terakhir yaitu peppermint (Mentha piperita) dikenal luas sebagai analgesik dan antiinflamasi, antiseptik, serta dapat memberi efek menyegarkan pada napas. ${ }^{12-14}$

Efektivitas pasta gigi herbal ini telah diteliti dan memperlihatkan hasil yang kontradiksi. Dinyatakan bahwa efektivitas pasta gigi herbal terhadap akumulasi plak maupun gingivitis dapat dikatakan setara jika dibandingkan dengan pasta gigi non-herbal. ${ }^{15}$ Sementara itu, walaupun pasta gigi herbal memiliki efektivitas yang lebih superior terhadap gingivitis, tetapi memiliki efektivitas yang setara terhadap akumulasi plak jika dibandingkan dengan pasta gigi non-herbal. ${ }^{11}$ Penelitian lain menunjukkan pasta gigi herbal lebih efektif terhadap akumulasi plak dan gingivitis dibandingkan pasta gigi non-herbal..$^{10,11,14,15}$ Hasil yang variatif dari beberapa penelitian tersebut mendorong peneliti untuk mengungkapkan efektivitas dari masing-masing pasta gigi. Penelitian ini, membandingkan kemampuan pasta gigi herbal dengan pasta gigi non-herbal dalam mengurangi akumulasi plak. Pasta gigi non-herbal yang digunakan, mengandung bahan aktif berupa sodium monofluorofosfat 1,12\% dan kalsium gliseofosfat 0,13\% akan dibandingkan dengan pasta gigi herbal. ${ }^{16}$

Tujuan penelitian ini adalah untuk mengetahui perbedaan indeks plak setelah pemakaian pasta gigi herbal pada pasien ortodonti dengan alat cekat, mengetahui perbedaan indeks plak setelah pemakaian pasta gigi non-herbal pada pasien ortodonti dengan alat cekat, dan untuk membandingkan efektivitas pasta gigi herbal dengan pasta gigi non-herbal terhadap akumulasi plak pada pasien ortodonti dengan alat cekat.

\section{METODE}

Pada penelitian ini digunakan rumus analitik numerik tidak berpasangan dengan tingkat kemaknaan sebesar 5\%, standar deviasi 0,06 dan besar kekuatan penelitian sebesar $90 \%$ sehingga diperoleh sampel per perlakuan sebanyak delapan subjek. ${ }^{10,17}$ Adapun kriteria inklusi dari penelitian ini adalah pasien ortodonti berusia 1535 tahun di RSGMP FKG UI, Departemen Ortodonti, yang akan menggunakan alat cekat dan ditangani oleh dokter Peserta Program Dokter Gigi Spesialis (PPDGS) Departemen Ortodonti FKG UI, memiliki gigi 16, 21, $25,36,41$, dan 45, kondisi kesehatan secara umum baik, memiliki motivasi untuk menjaga kebersihan mulut, bersedia membersihkan gigi hanya dengan teknik yang diajarkan, dan bersedia berpartisipasi dalam penelitian dengan menandatangani informed consent. Kriteria eksklusi penelitan ini antara lain subjek mengkonsumsi obat-obatan antibiotika dalam jangka waktu tiga bulan, sedang dalam masa kehamilan, memiliki penyakit sistemik, memiliki kebiasaan merokok, dan memakai alat prostodonti lepas.

Enam belas subjek yang memenuhi kriteria tersebut kemudian dibagi menjadi dua kelompok, kelompok yang menggunakan pasta gigi A (pasta gigi herbal) dan kelompok yang menggunakan pasta gigi B (pasta gigi non-herbal) dengan metode randomized clinical trial berdasarkan tabel blok randomisasi. Penelitian selanjutnya dilakukan dengan double-blind study. Pada penelitian ini baik kelompok pasta gigi A dan kelompok pasta gigi B menggunakan sikat gigi manual datar dengan teknik sikat gigi modifikasi Bass yang digabungkan dengan teknik modifikasi pasta gigi fluoride dengan frekuensi dua kali sehari dan durasi dua menit selama dua minggu. ${ }^{1,6,8,18-21}$ Teknik sikat gigi ini diajarkan secara langsung kepada setiap subjek penelitian dengan menggunakan model gigi dan memberikan lembar petunjuk teknik sikat gigi. Selain itu, subjek secara berkala diingatkan untuk menyikat gigi dengan menggunakan sikat, pasta gigi, dan teknik menyikat gigi yang telah diajarkan.

Pemeriksaan akumulasi plak yang pertama dilakukan dimana subjek belum menggunakan ortodonti dengan alat cekat (T0). Pemeriksaan akumulasi plak ini dilakukan dengan menggunakan indeks plak Löe dan Sillness pada gigi Ramfjord (16, 21, 25, 36, 41, dan 45). ${ }^{1,22}$ Selanjutnya dilakukan pemeriksaan kedua (T1), setelah subjek menggunakan ortodonti dengan alat cekat dan bersikat gigi selama dua minggu dengan sikat, pasta, dan teknik sesuai dengan yang diajarkan. Uji statistik pada penelitian ini menggunakan program SPSS untuk membandingkan nilai indeks plak sebelum dan setelah perlakuan baik pada kelompok pasta gigi A maupun kelompok pasta gigi B, dan juga untuk membandingkan selisih nilai indeks plak sebelum dan setelah perlakuan antara kelompok pasta gigi A dan B. 
Tabel 1. Distribusi data indeks plak berdasarkan waktu pemeriksaan

\begin{tabular}{ccccccccc}
\hline \multicolumn{2}{l}{ Waktu } & Perlakuan N & $\begin{array}{c}\text { Rata- } \\
\text { rata }\end{array}$ & $\begin{array}{c}\text { Simpang } \\
\text { Baku }\end{array}$ & Min Max & $\boldsymbol{p}$ \\
\hline \multirow{2}{*}{ T0 } & Pasta A & 8 & 0,615 & 0,30472 & 0,29 & 1,29 & \\
& & Pasta B & 8 & 0,615 & 0,43870 & 0,08 & 1,29 & \\
& Pasta A & 8 & 0,460 & 0,23250 & 0,13 & 0,71 & \\
\multirow{2}{*}{ T1 } & Pasta B & 8 & 0,916 & 0,53511 & 0,29 & 1,88 & \\
& & & & & & \multicolumn{4}{c}{0,065} \\
\hline
\end{tabular}

Tabel 2. Rerata nilai indeks plak per gigi berdasarkan waktu pemeriksaan

\begin{tabular}{cccccccccc}
\hline \multirow{2}{*}{ Waktu } & Perlakuan & \multicolumn{9}{c}{ Rata-rata Indeks Plak Per Gigi } & \multirow{2}{*}{ Total } \\
\cline { 2 - 7 } & & $\mathbf{1 6}$ & $\mathbf{2 1}$ & $\mathbf{2 5}$ & $\mathbf{3 6}$ & $\mathbf{4 1}$ & $\mathbf{4 5}$ & \\
\hline \multirow{2}{*}{ T0 } & Pasta A & 0.81 & 0.41 & 0.75 & 0.81 & 0.22 & 0.69 & 3.69 \\
& & Pasta B & 0.94 & 0.69 & 0.47 & 0.69 & 0.28 & 0.63 & 3.70 \\
\multirow{2}{*}{ T1 } & Pasta A & 0.50 & 0.31 & 0.66 & 0.44 & 0.22 & 0.66 & 2.79 \\
& & Pasta B & 0.84 & 0.50 & 1.09 & 1.25 & 0.53 & 1.28 & 5.49 \\
\hline
\end{tabular}

Tabel 3. Distribusi data indeks plak berdasarkan kelompok perlakuan

\begin{tabular}{ccccccccc}
\hline \multicolumn{2}{c}{ Kelompok Waktu N } & $\begin{array}{c}\text { Rata- Simpang } \\
\text { rata }\end{array}$ & Min & Max & $\boldsymbol{p}^{*}$ \\
\hline Pasta A & T0 & 8 & 0,615 & 0,30472 & 0,29 & 1,29 & 0,207 \\
& T1 & 8 & 0,460 & 0,23250 & 0,13 & 0,71 & \\
\multirow{2}{*}{ Pasta B } & T0 & 8 & 0,615 & 0,43870 & 0,08 & 1,29 & 0,091 \\
& T1 & 8 & 0,916 & 0,53511 & 0,29 & 1,88 & \\
\hline
\end{tabular}

*bermakna ( uji Wilcoxon, $p<0,05$ )

Tabel 4. Distribusi data selisih indeks plak berdasarkan kelompok perlakuan

\begin{tabular}{ccccccc}
\hline Kelompok N & $\begin{array}{c}\text { Rata- } \\
\text { rata }\end{array}$ & $\begin{array}{c}\text { Simpang } \\
\text { Baku }\end{array}$ & Min & Max & $\boldsymbol{p}^{*}$ \\
\hline Pasta A & 8 & $-0,1550$ & 0,26918 & $-0,62$ & 0,09 & 0,065 \\
Pasta B & 8 & 0,3012 & 0,40498 & $-0,25$ & 0,79 & \\
\hline
\end{tabular}

Pasta $\mathrm{A}=$ pasta gigi herbal; Pasta $\mathrm{B}=$ pasta gigi non-herbal

Uji kemaknaan menggunakan metode non-parametrik, Wilcoxon, dan Mann-Whitney.

\section{HASIL}

Hasil observasi yang dilakukan pada penelitian ini adalah bahwa pada awal penelitian, tidak terdapat perbedaan yang bermakna secara statistik $(p=0,789)$ antara indeks plak kelompok pasta gigi A dan kelompok pasta gigi B (Tabel 1). Setelah perlakuan, tetap tidak terlihat perbedaan yang bermakna secara statistik antara indeks plak kelompok pasta gigi A dan pasta gigi $\mathrm{B}(p=0,065)$. Penelitian ini juga memperlihatkan adanya perubahan nilai indeks plak setelah dua minggu pemakaian ortodonti cekat, terlihat bahwa akumulasi plak paling banyak terjadi pada gigi posterior (Tabel 2).

Melihat dari data sebelum dan sesudah perlakuan, pada kelompok pasta gigi A terlihat adanya kecenderungan penurunan indeks plak dari 0,615 menjadi 0,460 walaupun ternyata penurunan ini tidak berbeda bermakna secara statistik $(p=0,207)$. Pada kelompok pasta gigi B terlihat adanya kecenderungan peningkatan indeks plak dari 0,615 menjadi 0,916 yang secara statistik peningkatan tersebut juga tidak berbeda bermakna $(p=0,091)$ (Tabel 3). Data sebelum dan sesudah perlakuan memperlihatkan bahwa pada kelompok pasta gigi A terdapat penurunan indeks plak rata-rata sebesar 0,1550 dan sebaliknya pada kelompok pasta gigi B terlihat kecenderungan peningkatan indeks plak rata-rata sebesar 0,3012 .

\section{PEMBAHASAN}

Studi literatur serta penelitian menyatakan bahwa setelah pemakaian alat ortodonti cekat terjadi peningkatan akumulasi plak yang signifikan. ${ }^{23-25}$ Peningkatan ini terutama terjadi pada gigi posterior dikarenakan terdapatnya cincin ortodonti dan kawat ortodonti yang mempersulit penyikatan gigi di daerah tersebut. ${ }^{2,19,26,27}$ Peningkatan akumulasi plak setelah pemakaian alat ortodonti cekat ini juga terlihat pada kelompok pasta gigi B (pasta gigi non-herbal), sebaliknya pada kelompok pasta A (pasta gigi herbal) justru terlihat adanya penurunan indeks plak, sehingga dapat diasumsikan bahwa pasta gigi herbal yang mengandung sodium bikarbonat, fluoride, dan ekstrak bahan herbal dapat mengurangi akumulasi plak pada pasien ortodonti dengan alat cekat. Meskipun demikian, baik pada kelompok pasta gigi A maupun kelompok pasta gigi $\mathrm{B}$, perubahan nilai indeks plak tersebut ternyata tidak berbeda bermakna secara statistik.

Jika selisih indeks plak sebelum dan sesudah perlakuan pada kedua kelompok ini dibandingkan (Tabel 4) terlihat pasta A (pasta gigi herbal) lebih efektif dibandingkan dengan pasta $\mathrm{B}$ (pasta gigi non-herbal). Namun secara statistik, tidak terdapat perbedaan yang bermakna antara efektivitas kedua jenis pasta gigi tersebut. Hal ini sejalan dengan penelitian sebelumnya yang menyatakan bahwa tidak terdapat perbedaan yang signifikan secara statistik antara penggunaan pasta gigi herbal dan non-herbal, walaupun pasta gigi herbal menunjukkan penurunan indeks plak yang lebih banyak. ${ }^{15}$ Selain itu, penelitian lain juga menyatakan hal yang sama dalam pemakaiannya selama tiga minggu. ${ }^{11}$

Namun hasil penelitian ini bertentangan dengan penelitian lain yang menyatakan bahwa pasta gigi herbal lebih efektif terhadap akumulasi plak dari pada 
pasta gigi non-herbal yang berbahan dasar fluoride..$^{10,14}$ Penelitian sebelumnya menggunakan indeks plak Patient Hygiene Performance (PHP) yang berbeda dengan indeks yang digunakan pada penelitian ini. ${ }^{10}$ Perbedaan indeks plak yang digunakan inilah yang mungkin menyebabkan adanya perbedaan hasil yang diperoleh. Secara keseluruhan, penelitian ini menyimpulkan bahwa pasta gigi herbal memiliki efektivitas yang lebih baik dibandingkan dengan pasta gigi non-herbal terhadap akumulasi plak pada pasien ortodonti dengan alat cekat, tetapi perbedaan efektivitas tersebut tidaklah bermakna secara statistik.

\section{SIMPULAN}

Walaupun terlihat adanya kecenderungan peningkatan indeks plak, tetapi secara statistik tidak terdapat perbedaan indeks plak yang bermakna antara sebelum dan setelah pemakaian pasta gigi non-herbal pada pasien ortodonti dengan alat cekat. Meskipun kelompok perlakuan pasta gigi herbal memperlihatkan adanya kecenderungan penurunan indeks plak dan sebaliknya kelompok perlakuan pasta gigi non-herbal memperlihatkan kecenderungan peningkatan indeks plak, namun secara statistik tidak bermakna. Hal yang penting dalam menjaga kebersihan mulut pada pasien ortodonti dengan alat cekat ialah motivasi pasien sendiri dalam menjaga kebersihan mulut dengan teknik yang benar.

\section{DAFTAR PUSTAKA}

1. Wilkins EM. Clinical practice of the dental hygienist. 9th ed. Baltimore: Lippincott Williams \& Wilkins; 2005.

2. Ahn SJ, Lim BS, Lee SJ. Prevalence of cariogenic streptococci on incisor brackets detected by polymerase chain reaction. Am J Orthod Dentofac Orthop. 2007; 131:736-41.

3. Chin MY, Busscher HJ, Evans R, Noar J, Pratten J. Early biofilm formation and the effects of antimicrobial agents on orthodontic bonding materials in a parallel plate flow chamber. Eur J Orthod. 2006;28:1-7.

4. Mount GJ, Hume WR. Preservation and restoration of tooth structure. 2nd ed. Australia: Knowledge Books and Software; 2005.

5. Newman MG, Takei HH, Klokkevold PR, Carranza FA. Clinical periodontology. 10th ed. Missouri: Elsevier; 2006.

6. Schatzle M, Imfeld T, Sener B, Schmidlin PR. In vitro tooth cleaning efficacy of manual toothbrushes around brackets. Eur J Orthod. 2009;31:103-7.

7. Asadoorian J. CDHA position paper on tooth brushing. Can J Dent Hyg. 2006;40:232-48.

8. Gallagher A, Sowinski J, Bowman J, Barrett K, Lowe S, Patel K, et al. The effect of brushing time and dentrifice on dental plaque removal in vivo. $\mathrm{J}$
Dent hygene. 2009;83:111-6.

9. Dodwad V, Malhotra S, Nayyar N. Toothpaste wars: to assess the efficacy of a herbal, homeopathic and a conventional toothpaste in the control of plaque and gingivitis - a clinico-biochemical study. Ind $\mathrm{J}$ Stomatol. 2011;2:91-4.

10. Al-Kholani AI. Comparison between the efficacy of herbal and conventional dentrifices on established gingivitis. Dent Res J. 2011;8:57-63.

11. Pannuti CM, Mattos JP, Ranoya PN, Jesus AM, Romito GA, Lotufo RFM. Clinical effect of a herbal dentrifice on the control of plaque and gingivitis. Pesqui Odontol Bras. 2003;17:314-8.

12. Mandel ID. The new toothpaste. J Calif Dent Assoc. $1998 ; 26: 286$.

13. Herbal toothpaste gets tough on plaque [Internet]. [cited 2011 Aug 1]. Available from: http://www. bastyrcenter.org/content/view/1110.

14. Radafshar G, Mahboob F, Kazemnejad E. A study to assess the plaque inhibitory action of herbal-based toothpaste: a double blind controlled clinical trial. J Med Plants Res. 2011;4:1182-6.

15. Ozaki F, Pannuti CM, Imbronito AV, Pessotti W, Saraiva L, De Freitas NM, et al. Efficacy of a herbal toothpaste on patients with established gingivitis - a randomized controlled trial. Braz Oral Res. 2006;20:172-7.

16. Unilever Indonesia [Internet]. [cited 2011 Aug 11]. Available from: http:/unilever.co.id/id/brands/ personalcarebrands/pepsodent/index.aspx.

17. Sastroasmoro S, Ismael S. Dasar-dasar metodologi penelitian klinis. 2nd ed. Jakarta: Sagung Seto; 2002. Indonesian.

18. Christersson LA, Grossi SG, Dunford RG, Machtei EE, Genco RJ. Dental plaque and calculus: risk indicators for their formation. J Dent Res. 1992;71:1425-30.

19. Costa MR, da Silva VC, Miqui MN, Colombo APV, Cirelli JA. Effects of ultrasonic, electric and manual toothbrushes on subgingival plaque composition in orthodontically banded molars. Am J Orthod Dentofacial Orthop. 2010;137:229-35.

20. Poyato-Ferrera M, Segura-Egea JJ, Bullon-Fernandez P. Comparison of modified bass technique with normal toothbrushing practices for efficacy in supragingival plaque removal. Int J Dent Hyg. 2003;1:110-4.

21. Al Mulla AH, Kharsa SA, Birkhed D. Modified fluoride toothpaste technique reduces caries in orthodontic patients: a longitudinal, randomized clinical trial. Am J Orthod Dentofacial Orthop. 2010;138:285-91.

22. Wolf HF, Hassell TM. Color atlas of dental hygiene: periodontology. Grammlich: Thieme; 2006.

23. Lara-Carillo E, Montiel-Bastida NM, Sachez-Perez L, Alanis-Tavira J. Effect of orthodontic treatment on saliva, plaque and the levels of Streptococcus mutans and lactobacillus. Med Oral Patol Oral Cir Bucal. 2010;15:e924-9.

24. Turkkahraman H, Sayin MO, Bozkut FY, Yetkin 
Z, Kaya S, Onal S. Archwire ligation techniques, microbial colonozation and periodontal status in orthodontically treated patients. Angle Orthod. 2005;75:231-6.

25. Chang HS, Walsh LJ, Freer TJ. Enamel demineralization during orthodontic treatment. Aetiology and prevention. Aust Dent J. 1997;42:3227.
26. Aloufi F, Ciancio SG, Shilby O, Al-Zahrani MS. Plaque accumulation in adolescent orthodontic patients: bonded versus banded teeth. Dent Learning. 2010;4:1-3.

27. Tufekci E, Dixon JS, Gunsolley JC, Lindauer SJ. Prevalence of white spot lesions during orthodontic treatment with fixed appliance. Angle Orthod. 2011;81:206-10. 